\title{
Solange Hibbs-Lissorgues. El liberalismo es Pecado Pagès Editors, Lleida, España, 2009.
}

\section{Fabián Bustamante Olguín ${ }^{1}$}

\author{
Reseña \\ Fecha de recepción: 1 de julio de 2013 \\ Fecha de aprobación: 17 de octubre de 2013
}

El libro que nos presenta, en esta ocasión, la editorial Pagès pertenece a la colección de Historia El Fil D'Ariadna, que constituye una interesante edición crítica de uno de los principales referentes del integrismo católico: el presbítero catalán Félix Sardá y Salvany (1844-1916), autor del opúsculo apologético El liberalismo es Pecado: cuestiones candentes, publicado en 1884, uno de los más polémicos best-sellers de la literatura española de finales del siglo XIX, que gozó de gran difusión entre los círculos integristas.

La idea fundamental de la cual parte Solange Hibbs-Lissourgues es cómo el fundamentalismo religioso se expresó a través de un lenguaje puesto al servicio de una Iglesia Católica dispuesta a la violencia ante cualquier amenaza a sus dogmas. Partiendo de esta interrogante, es preciso señalar que la autora contextualiza el período histórico caracterizado por una profunda crisis dentro del catolicismo español, producto de las diversas disputas semánticas de "lo católico" por parte de los sectores que intentaban trazar puentes con el liberalismo (mestizos) y otros que insistían

1 Bachiller en Ciencias Sociales y Humanidades y Licenciado en Historia, Universidad Diego Portales. Magíster en Historia, Universidad de Santiago de Chile. Editor de la Revista Cultura y Religión, Instituto de Estudios Internacionales (INTE), Universidad Arturo Prat. Profesor adjunto de la Escuela de Sociología, Universidad Católica Silva Henríquez. 
en la necesidad de mantener la unión de la Iglesia y el Estado (integristas y carlistas).

En este marco, Hibbs-Lissourgues dibuja la intención de Sardá de recatolizar la sociedad española utilizando los elementos propios de la modernidad como la prensa y la propaganda, pero también de otros medios como las Academias de Juventud Católica, sociedades de caridad, cofradías piadosas, bibliotecas populares, etcétera.

En tal línea se encontraba la Revista Popular (fundada y dirigida por Sardá y Salvany hasta su muerte en 1916), una de las publicaciones semanales católicas que mayor influencia ejerció en las polémicas político-religiosas del último cuarto de siglo en España, que combatió el liberalismo y esgrimió a favor de un regreso del poder de la Iglesia por sobre la sociedad a través de una "santa cruzada".

Con respecto a Hibbs-Lissorgues, cabe subrayar que ella es licenciada de Lingüística y de Literatura y Lenguas Españolas y Doctora por la Universidad de Toulouse 2-Le Mirail, Francia, y tiene una dilatada experiencia en la investigación de la prensa y literatura católica del período de la Restauración, con una numerosa cantidad de publicaciones respecto a este tema. Consecuentemente con esas investigaciones, la autora ha puesto su interés en el libro de Sardá para indagar la instrumentalización de la religión en la justificación de la intolerancia, la violencia y la instauración de regímenes autoritarios.

Así, pues, la autora articula su libro en dos partes. En su primera parte, Estudio preliminar: El Integrismo, ofrece un panorama claro del complejo desarrollo del integrismo católico en la Península Ibérica y Europa. En este plano la autora destaca algunos acontecimientos ocurridos en el catolicismo europeo que repercutieron en España, tales como el Syllabus en 1864; el Concilio Vaticano I (1869-1870); la advertencia del Papa León XIII a los integristas españoles en la encíclica Cum Multa de 1882 o la Inmortale Dei que alentaba a los católicos a colaborar políticamente con los 
regímenes liberales. Esta última encíclica, por cierto, permitió el acercamiento del catolicismo con el liberalismo en países como Francia y Bélgica, y en menor medida en España.

Cabe señalar que en este último país tal acercamiento se vio obstaculizado por el peso del pensamiento tradicionalista influenciado por autores como Juan Donoso Cortés (en especial su obra Ensayo sobre el catolicismo, el liberalismo y el socialismo, considerados en sus principios fundamentales, de 1851) que planteaba la tesis de que la unidad nacional se basaba en la unidad católica, cuestión que alimentó el mito de la raza española que se impuso en todo momento ante las "herejías extranjerizantes" como el liberalismo.

Tales premisas ideológicas, por tanto, constituyeron -a juicio de Hibbs-Lissourgues- un terreno fértil para el desarrollo del nacionalcatolicismo. Ideología que alimentó a la cultura política de la derecha antiliberal de los siglos XIX y XX. De hecho tal ideología justificó la "cruzada" del general Francisco Franco contra la Segunda República y el régimen omnímodo que instauró a partir de 1939.

Sentado lo anterior, la autora concluye que Liberalismo es Pecado constituyó el marco teórico de los sublevados durante la Guerra Civil española, y además porque sus ideas contenidas cimentaron los elementos del nacionalcatolicismo, a saber: el mito de la raza española y la unión entre fe católica e identidad nacional.

A este respecto, cabe señalar que tales mitos fueron recepcionados en nuestro país a través del hispanismo que se constituyó en una corriente ideológica expandida por el franquismo durante la década del cuarenta en América Latina, y en la cual basaba sus supuestos en torno a una comunidad o raza transatlántica unida por un estilo de vida, cultura, características, tradiciones y valores que España trasplantó al continente americano.

La señalada ideología permitió a España ser el guía espiritual y cultural de esta comunidad que tuvo en Chile a sus máximos 
difusores en el ámbito de la cultura como el historiador Jaime Eyzaguirre y el sacerdote Osvaldo Lira, ambos difusores del integrismo católico y admiradores de los pensadores tradicionalistas españoles como Ramiro de Maeztu y Juan Vázquez de Mella. Además fueron profesores de toda una generación de políticos e intelectuales de derecha, entre los cuales se pueden mencionar a Jaime Guzmán Errázuriz, intelectual orgánico de la dictadura de Pinochet y fundador de la Unión Demócrata Independiente (UDI). Demás está decir que Guzmán perteneció al grupo integrista Fiducia durante la década del sesenta, en donde ya perfilaba el modelo autoritario de sociedad.

Otro aspecto a tener en cuenta es la tesis que subyace en el primer eje del libro que plantea que la recatolización de Sardá en los sectores obreros solucionó el problema de la inserción de las clases dominantes hacia el proletariado, con el propósito de frenar la injerencia de corrientes socialistas y anarquistas en su seno. Lo que permite señalar, con toda coherencia, que las ideas de Sardá -en tanto visión jerárquica de la sociedad- sirvieron de control social por parte de las elites hacia esos sujetos populares.

Lo señalado refiere a la tesis de la religión como ideología de la clase dominante, en la que no sólo se concentraba en lo espiritual sino que resultaba funcional al mantenimiento del statu quo de la elite dirigente. De modo que -siguiendo a Hibbs-Lissorgues- Sardá pretendía desacreditar las doctrinas marxistas para así destacar el mensaje popular del catolicismo. Por ello la autora sostiene que si bien la revista admitía la existencia de clases desheredadas y se reconocían las quejas de los pobres, tal sensibilidad apuntaba más a una reacción de defensa del orden existente que a una búsqueda de una alternativa doctrinal.

Por otro lado, la segunda parte del libro reproduce El Liberalismo es Pecado, donde Sardá arremetió contra cualquier actitud tolerante con el liberalismo, en los mismos días en que el Papa León XIII postulaba la necesidad de los católicos españoles de unir fuerzas para actuar en la vida pública. De ahí la actitud 
intransigente de Sardá por los católicos liberales infiltrados en las filas católicas y -quizás- los enemigos más peligrosos para el integrismo. Ello, por cierto, como consecuencia de que el liberalismo, en todas sus expresiones -según el punto de vista del sacerdote catalán-, constituiría la antítesis de la soberanía real de Jesucristo, enemiga de todo culto religioso, por lo demás.

Para finalizar esta reseña, no cabe duda que este libro será una herramienta útil para todos aquellos que trabajan el tema religión y política. En ese sentido pensamos que el integrismo católico español tuvo una notable acogida en los países latinoamericanos que se expresó en elementos centrales de su ideología como el antiliberalismo, el corporativismo y la interpretación teológico-política de la historia. Todos estos componentes justificaron las violencias extremas desde el Estado durante la década del setenta y ochenta en América Latina.

Por último, es digno de elogio el rigor del que Solange HibbsLissourgues ha hecho gala en su larga dedicación al estudio de la prensa y literatura católica del siglo XIX español, cristalizado en esta edición crítica de El liberalismo es pecado, un libro que transmite una sensación de solidez, digna de agradecimiento. 